\title{
Caracterização pós-colheita de figos (Ficus carica L.) produzidos sob diferentes condições de cultivo na Chapada do Apodi - CE
}

\section{Description post-harvest of figs (Ficus carica L.) produced under protected cultivation and open skies the Apodi Plateau - CE}

\author{
Raniely N. S. Freitas ${ }^{*}$, Pahlevi A. Souza ${ }^{2}$, Monique E. T. Silva ${ }^{3}$, Francisco L. Silva ${ }^{4}$, Patrício B. Maracajá 5 .
}

\begin{abstract}
Resumo: A produção de figos para consumo in natura é limitada pelas chuvas, que causam elevadas perdas por podridão, o que pode dificultar o seu cultivo durante a estação chuvosa local (fevereiro a maio), época em que a fruta atinge a sua maior cotação. Essa dificuldade poderá ser contornada com o uso de ambiente protegido. Objetivou-se com o presente trabalho, realizar a caracterização da qualidade pós-colheita de figos produzidos sob cultivo protegido e a céu aberto na Chapada do Apodi- CE. Os frutos utilizados neste experimento foram colhidos em pomar experimental da Unidade de Ensino e Pesquisa (UEPE), pertencente ao Instituto Federal de Educação, Ciência e Tecnologia do Ceará (IFCE), localizada na Chapada do Apodi em Limoeiro do Norte - Ceará, onde os mesmos foram cultivados a céu aberto e em estufa. Foram realizadas as seguintes análises: diâmetro do fruto, peso do fruto, firmeza da polpa, sólidos solúveis (SS), acidez titulável(AT), pH, RATIO e vitamina C. De acordo com os parâmetros analisados, os figos cultivados em estufa apresentaram melhores atributos físico-químicos em relação aos cultivados em céu aberto, concluindo-se que, o tipo de cultivo influencia na qualidade pós-colheita do fruto.
\end{abstract}

Palavras-chave: Céu aberto, estufa, qualidade.

Abstract: The production of figs for fresh consumption is limited by rainfall, causing high losses, which can impede its cultivation during the rainy season site (February-May), at which time the fruit reaches its highest price. This difficulty can be circumvented with the use of a greenhouse. The objective of the present work to characterize the post-harvest quality of figs produced in greenhouses and open the Apodi Plateau-CE. The fruits used in this experiment were collected in an experimental orchard and Teaching Unit Search (UEPE) belonging to the Federal Institute of Education, Science and Technology of Ceara (IFCE), located in the Apodi Plateau in North Limon - Ceará, where they were grown in the open and under glass.The following analyzes were performed: fruit diameter, fruit weight, firmness, soluble solids (SS), titratable acidity (TA) and pH. According to the parameters analyzed, figs grown in the greenhouse showed better physical and chemical attributes in relation to grown in the open air, concluding that the type of crop influences on post-harvest quality of the fruit.

Keywords: Comparison, production, quality

\footnotetext{
*Autor para correspondência

Recebido para publicação em 01/02/2015; aprovado em 30/02/2015

${ }^{1}$ Mestranda em Tecnologia em Alimentos - IFCE/Limoeiro do Norte - CE. ranielyfreitas5@gmaill.com

${ }^{2}$ Eng. Agr. D. Sc. em Fitotecnia. Professor Efetivo do Instituto Federal, IFCE - Campus Limoeiro do Norte. E-mail: pahlevi@ifce.edu.br

${ }^{3}$ Mestranda em Tecnologia em Alimentos - IFCE/Limoeiro do Norte - CE. E-mail: metorres08@hotmail.com

${ }^{4}$ Dr. em Engenharia Agrícola. . Professor Efetivo do Instituto Federal, IFCE - Limoeiro do Norte. URL da Homepage: http://www.ifce.edu.br

${ }^{5}$ Eng. Agr. D. Sc. em Entomologia . Professor associado IV da Universidade Federal de Campina Grande - CCTA - Campus de Pombal - PB. E-mail: patricio@ufersa.edu.br.
} 


\section{INTRODUÇ̃̃O}

O figo (Ficus carica L.) se apresenta como grande potencial para ser o próximo atrativo da cultura cearense. A fruta foi trazida de regiões produtoras de São Paulo a título de experimentação, em uma área de quatro hectares, e manifestou alto potencial produtivo adaptando-se muito bem às condições climáticas da Chapada do Apodi.

Em consequência, o governo do estado planeja expandir o seu cultivo visando um aumento de renda para os pequenos agricultores cearenses que dispõem de área com irrigação. Entretanto, a produção de figos para consumo in natura é limitada pelas chuvas, que causam elevadas perdas por podridão, o que pode dificultar o seu cultivo durante a estação chuvosa local (fevereiro a maio), época em que a fruta atinge a sua maior cotação.

Essa dificuldade poderá ser contornada com o uso de ambiente protegido, que possibilita também economia de água devido à redução da evapotranspiração da cultura, mas pode ser inviável economicamente para o pequeno produtor. Problema este que pode ser resolvido com o uso de latadas de baixo custo, construídas em parte com material disponível na propriedade. Darezzo et al. (2004) reporta que a tecnologia do cultivo protegido vem a somar às novas tecnologias empregadas na agricultura, com a finalidade de buscar respostas ao desafio de produzir alimentos de maneira competitiva e sustentável, elevando a produtividade e a qualidade dos produtos, aumentando a lucratividade com um mínimo de impacto ao meio ambiente e assim, diminuindo os riscos e as incertezas agrícolas.

De acordo com estudos de Nienow et al. (2006), o cultivo do figo em ambiente protegido permitiu ampliar o período de safra, evitou perdas por podridão e rachaduras de frutos, causadas pelas frequentes chuvas no período de colheita.

Desse modo, a realização deste trabalho teve como objetivo caracterizar a qualidade pós-colheita de figos produzidos sob cultivo protegido e a céu aberto na chapada do Apodi, no município de Limoeiro do Norte - CE.

\section{MATERIAL E MÉTODOS}

Os frutos utilizados neste experimento foram colhidos em pomar experimental da Unidade de Ensino e Pesquisa (UEPE), pertencente ao Instituto Federal de Educação, Ciência e Tecnologia do Ceará (IFCE), localizado no na Chapada do Apodi em Limoeiro do Norte - Ceará, onde os mesmos foram cultivados a céu aberto e em estufa. A estufa agrícola possuía as seguintes características: altura na parte central de 4,20 e 3,0 $\mathrm{m}$ de pé direito, a estrutura construída em madeira, com teto em forma de arco de elipse de ferro galvanizado e cobertura com polietileno de baixa densidade e tela de sombreamento. As laterais foram fechadas com tela, com espaços de $3,0 \mathrm{~mm}$. O ambiente a céu aberto teve a mesma dimensão de superfície, ou seja, $32 \mathrm{~m}$ de comprimento e $6,4 \mathrm{~m}$ de largura. Após a colheita, os frutos foram acondicionados em recipientes adequados e transportados para o Laboratório de Química do Instituto Federal de Educação, Ciência e Tecnologia do Ceará - IFCE Campus de Limoeiro do Norte, para realização das análises. As características avaliadas foram: a) Diâmetro do fruto - Foi determinado em com a utilização de paquímetro manual sendo os valores expressos em $\mathrm{mm}$.

b) Peso do fruto - Os frutos foram pesados em balança semianalítica (marca BEL, modelo Mark 3.100) sendo os valores expressos em $\mathrm{g}$.

c) Firmeza da polpa - Obtida com penetrômetro manual tipo McCormick modelo FT 327, com valor máximo de leitura 29 $\mathrm{lb} / \mathrm{pol}^{2}$ com ponteira de $8 \mathrm{~mm}$ de diâmetro. Foram realizadas duas leituras na polpa, no região equatorial do fruto em regiões equidistantes, com os resultados obtidos em libra e depois transformados em Newton (N) através da multiplicação pelo fator 4,448 .

d) Sólidos solúveis (SS) - O conteúdo de SS foi determinado por leitura em refratômetro digital Atago, modelo PR-100, com escala variando de 0 até $45^{\circ}$ Brix, com compensação automática de temperatura, tomando duas gotas do filtrado após homogeneização das fatias dos frutos em multiprocessador doméstico, e registrado com precisão de 0,1 a $25^{\circ} \mathrm{C}$ conforme AOAC (1992). Os resultados foram expressos em percentagem ( ${ }^{\circ}$ Brix).

e) Acidez titulável (AT) - A acidez titulável (AT) foi realizada por titulação em duplicata usando-se 5,0 g da amostra de suco, ao qual foi adicionado $50 \mathrm{~mL}$ de água destilada, utilizando-se uma solução de $\mathrm{NaOH}$ à $0,1 \mathrm{~N}$, previamente padronizada. Os resultados foram expressos em percentagem (\%) de ácido cítrico (INSTITUTO ADOLFO LUTZ, 2008).

f) $\mathrm{pH}-\mathrm{O}$ potencial hidrogeniônico $(\mathrm{pH})$ foi determinado diretamente no suco, utilizando-se um potenciômetro digital (modelo HI 9321 da Hanna Instruments) calibrado com soluções tampão de pH 4,0 e 7,0.

g) RATIO (Relação SS/AT) - Foi determinada pelo quociente das características SS e AT.

h) Vitamina C - A vitamina $C$ total foi avaliada por titulação direta com solução de Tillman (2,6 diclorofenol indofenol DFI), conforme metodologia de Strohecker e Henning (1967), usando-se 5,00 g da amostra do suco completando-se o volume para $50 \mathrm{~mL}$ em balão volumétrico com ácido oxálico $0,5 \%$. Posteriormente, em duplicata, foram retiradas $5 \mathrm{~mL}$ e colocou-se em Erlenmeyer de $125 \mathrm{~mL}$, completando-se o volume para $50 \mathrm{~mL}$ com água destilada, titulou-se com a solução de Tillman, refrigerada, até o ponto de viragem levemente róseo permanente. Os resultados foram expressos em mg de vitamina $\mathrm{C}$ por $100 \mathrm{~g}$ de polpa.

O delineamento utilizado foi o DIC (Delineamento Inteiramente Casualizado) com quatro repetições e cinco frutos por parcela, sendo os dados submetidos à análise de variância utilizando-se $\mathrm{o}$ teste de Tukey a $5 \%$ de probabilidade.

\section{RESULTADOS E DISCUSSÃO}

Para a característica peso dos frutos, observou-se diferença significativa entre os tratamentos estudados com os frutos cultivados na estufa apresentando-se mais pesados (Tabela 1). O figo cultivado a céu aberto apresentou uma redução de peso de $29,7 \%$ em relação aos cultivados na estufa, provavelmente devido a maior perda de umidade. Nienow et al. (2006), estudando a produção da figueira em ambiente protegido submetida a diferentes épocas de poda e número de ramos, verificaram peso médio de $52,0 \mathrm{~g}$, inferior ao peso médio dos figo cultivados em estufa no presente trabalho. 
Tabela 1. Características físico-químicas de Figos (Ficus carica L.) cultivados em estufa e a céu aberto em Limoeiro do Norte - CE - IFCE, 2012.

\begin{tabular}{|c|c|c|c|c|}
\hline \multirow[b]{2}{*}{ CARACTERÍSTICAS AVALIADAS } & \multicolumn{4}{|c|}{ TRATAMENTOS } \\
\hline & Estufa & Céu aberto & Média Geral & C.V (\%) \\
\hline Peso $(g)$ & $58,97 \mathrm{a}^{*}$ & $41,41 \mathrm{~b}$ & 50,19 & 12,05 \\
\hline Diâmetro transversal $(\mathrm{cm})$ & $52,2 \mathrm{a}$ & $45,8 \mathrm{~b}$ & 4,89 & 4,29 \\
\hline Diâmetro longitudinal $(\mathrm{cm})$ & $55,7 \mathrm{a}$ & $52,9 \mathrm{a}$ & 5,43 & 5,96 \\
\hline Firmeza $(\mathrm{N})$ & $1,36 \mathrm{~b}$ & $2,36 \mathrm{a}$ & 1,86 & 22,57 \\
\hline Sólidos Solúveis ( $\left.{ }^{\circ} \mathrm{Brix}\right)$ & $12,65 \mathrm{a}$ & $9,72 \mathrm{~b}$ & 11,18 & 12,71 \\
\hline Acidez titulável( $\%$ de ác. cítrico) & $0,114 \mathrm{a}$ & $0,161 \mathrm{a}$ & 0,138 & 22,41 \\
\hline $\mathrm{pH}$ & $5,44 \mathrm{a}$ & $5,28 \mathrm{a}$ & 5,36 & 4,46 \\
\hline RATIO (SS/AT) & $88,79 \mathrm{a}$ & $63,10 \mathrm{a}$ & 75,94 & 38,70 \\
\hline Vitamina $\mathrm{C}(\mathrm{mg} / 100 \mathrm{~g}$ de polpa) & $12,12 \mathrm{a}$ & $10,39 \mathrm{a}$ & 11,25 & 12,06 \\
\hline
\end{tabular}

* Médias seguidas da mesma letra nas linhas não diferem entre si pelo Teste de Tukey a $5 \%$ de probabilidade.

Em relação aos diâmetros transversal e longitudinal dos frutos, houve diferença significativa apenas para o primeiro com maiores valores para os frutos cultivados em estufa (Tabela 1). Os figos cultivados em estufa podem ter atingido o seu desenvolvimento completo mais cedo que os frutos cultivados a céu aberto, dessa forma atingindo um maior diâmetro transversal. Segundo as Normas de Classificação para o Figo do Programa Brasileiro para a Modernização da Agricultura (HORTBRASIL, 2012), o tamanho do fruto é determinado pelo maior diâmetro transversal do fruto e a homogeneidade do lote é garantida pela obediência à amplitude de variação do diâmetro permitida em cada classe. Segundo a mesma cartilha de classificação, existem 5 classes relacionadas ao diâmetro do fruto: 40, 45, 50, 55 e $65 \mathrm{~mm}$. No presente trabalho, os figos cultivados em estufa encontram-se na classe 50 (entre 50 e 55 $\mathrm{mm}$ ) e os cultivados a céu aberto encontram-se na classe 45 (entre 45 e $50 \mathrm{~mm}$ ).

Houve diferença significativa para a característica firmeza da polpa entre os tratamentos (Tabela 1). Os frutos cultivados a céu aberto apresentaram-se mais firmes que os cultivados em estufa, possivelmente por causa dos frutos mantidos em estufa terem amadurecido mais cedo e perdido menos umidade que os mantidos a céu aberto. Lima et al. (2005), estudando o armazenamento de figos verdes cv. Roxo de Valinhos observaram variação da firmeza da polpa de $10,58 \mathrm{~N}$ no ato da colheita a $5,0 \mathrm{~N}$ aos 35 dias de armazenamento. Segundo Mathooko et al. (1993), a perda de firmeza de figos é decorrente da ação de enzimas que atuam na hidrólise do amido, da transformação dos constituintes celulósicos da parede celular, bem como da conversão da protopectina em pectina solúvel e excessiva perda de água dos frutos.

Os teores de sólidos solúveis (SS) diferiram estatisticamente entre os tratamentos estudados (Tabela 1). Os frutos cultivados em estufa apresentaram teores mais elevados de SS que os cultivados a céu aberto, provavelmente por terem atingido o amadurecimento completo, ou seja, ter havido a hidrolise do amido e formação de açúcares solúveis. Paula et al. 2007 relatam teores de SS entre 14,37 e 15,64 ${ }^{\circ}$ Brix em figos da cultivar Roxo-de-Valinhos, tratados com aplicação pós-colheita de cloreto de cálcio, assim como do uso de dois tipos de fungicidas.

Não verificou-se diferença significativa entre os tratamentos para a característica acidez titulável (Tabela 1). Em média os frutos cultivados a céu aberto apresentaram maiores teores de acidez, sendo causado, principalmente pela perda umidade. Para Chitarra (1998) a acidez é modificada por alterações nas concentrações dos ácidos orgânicos que ocorrem durante o crescimento e diferencia-se em cada tipo de fruto.

Em relação ao $\mathrm{pH}$ das amostras, não houve diferença significativa entre os frutos cultivados a céu aberto e os cultivados em estufa. Os valores encontrados de 5,44 e 5,28 para os figos em cultivo protegido e não protegido, respectivamente, estão de acordo com Gonçalves et al. 2006, que em seu estudo encontrou valores de 5,91 a 5,45 para frutos maduros.

Não houve diferença significativa para a relação entre os SS e a AT (tabela 1). Porém, em valores médios os frutos cultivados em estufa apresentaram maiores valores $(88,79)$ em relação os cultivados a céu aberto $(63,10)$. Segundo Chitarra e Chitarra (2005) a alta relação SS/AT é muito importante e desejável nos frutos, sendo uma das formas mais utilizadas para a avaliação do sabor.

Os teores de vitamina $\mathrm{C}$ não diferiram estatisticamente entre os tratamentos estudados (Tabela 1). Em média os frutos cultivados em estufa apresentaram maiores teores de vitamina $C$ com teor de $12,12 \mathrm{mg} / 100 \mathrm{~g}$ de polpa. Em pesquisa recente, Silva et al. 2013, encontraram teores de ácido ascórbico de 13,71, 10,48 e 18,03 mg ácido ascórbico/100g para o blend de mamão e fígo-da-índia nas concentrações de $25 \%, \quad 50 \%$ e $75 \%$ de mamão, respectivamente. Os figos não apresentam teores elevados de vitamina $\mathrm{C}$ como ocorre em outros frutos como caju, acerola entre outros.

\section{CONCLUSÃo}

A partir dos resultados obtidos, os figos cultivados em estufa apresentaram melhores atributos físico-químicos em relação aos cultivados em céu aberto, com isso, pode-se concluir que o tipo de cultivo influencia na qualidade póscolheita do fruto, sendo o cultivo em ambiente protegido uma excelente alternativa para produção de figos com elevada qualidade.

\section{REFERÊNCIAS BIBLIOGRÁFICAS}

Association of Official Analytical Chemistry. Official methods of analysis of the Association of Official Analytical Chemistry. 17. ed. Washington: AOAC, 1115p. 1992. 
CHITARRA, M. I. F. Colheita e qualidade de produtos vegetais. UFLA/SBEA, Poços de Caldas, p.58, 1998.

CHITARRA, M. I. F.; CHITARRA, A. B. Pós - colheita de frutos hortaliças: fisiologia e manuseio. UFLA, Lavras, 2. ed. p. 785, 2005.

DAREZZO, R. J.; AGUIAR, R. L.; AGUILERA, G. A. H.; ROZANE, D. E.; Silva, D. J. H. da. Cultivo em ambiente protegido: histórico, tecnologias e perspectivas. UFV, Viçosa-MG, p.332, 2004.

GONÇALVES, C. A. A.; LIMA, L. C. O.; LOPES, P. S. N.; SOUZA, M. T. Poda e sistemas de condução na produção de figos verdes. Pesquisa Agropecuária Brasileira, Brasília, v. 41, n. 6, p. 995-961, 2006.

HORTBRASIL. Normas de classificação para o Figo. Disponível em: http://www.hortibrasil.org.br/jnw/images/stories/folders/ figo.pdf. Acesso em 22/07/2012.

Instituto Adolfo Lutz (São Paulo). Métodos físico-químicos para análise de alimentos - São Paulo: Instituto Adolfo Lutz, 2008.

LIMA, L. C.; Dias, M. S. C.; CASTRO, M. V.; MARTINS, R. N.; RIBEIRO JÚNIOR, P. M.; SILVA, E. B. Conservação pós-colheita de figos verdes (Ficus carica L.) cv. Roxo de Valinhos tratados com hipoclorito de sódio e armazenados sob refrigeração em atmosfera modificada passiva. Ciênc. agrotec., v. 29, n. 4, p. 810816, 2005.

MATHOOKO, F. M.; SOTOKAMA, T.; KUBO, Y.; INABA, A.; NAKAMURA, R. Retention of freshness in fig fruit by $\mathrm{CO}_{2}$, enriched atmosphere. Japan Society Hortculture Science, Okayama, v. 62, n. 3, p. 661-667, 1993.

NIENOW, A. A.; SACOMORI, M. D. F. Crescimento e produção da figueira cv. Roxo de Valinhos conduzida em ambiente protegido. Passo Fundo - RS. In: Reunião Técnica de Fruticultura, 6, 2006, Bagé.

PAULA, L. A.; ISEPON, J. S.; CORRÊA, L. S. Qualidade pós-colheita de figos do cv Roxo-de-Valinhos com aplicação de cloreto de cálcio e fungicidas. Acta Scientiarum Agronomy, Maringá, v. 29, n. 1, p. 41-46, 2007.

SILVA, F. S.; FIGUEIRÊDO, R. M. F.; QUEIROZ, A. J. M.; LEMOS, D. M.; LIMA, J. C. B. Caracterização de blends de mamão formosa e figo-da-índia. Revista Verde, Mossoró - RN, v. 7, n. 3, p. 202 - 206, 2013. 